\title{
Gamma distribution models for transit time estimation in catchments: Physical interpretation of parameters and implications for time-variant transit time assessment
}

\author{
M. Hrachowitz, ${ }^{1,2}$ C. Soulsby, ${ }^{1}$ D. Tetzlaff, ${ }^{1}$ I. A. Malcolm, ${ }^{3}$ and G. Schoups ${ }^{2}$ \\ Received 27 January 2010; revised 23 June 2010; accepted 6 July 2010; published 23 October 2010.
}

[1] In hydrological tracer studies, the gamma distribution can serve as an appropriate transit time distribution (TTD) as it allows more flexibility to account for nonlinearities in the behavior of catchment systems than the more commonly used exponential distribution. However, it is unclear which physical interpretation can be ascribed to its two parameters $(\alpha, \beta)$. In this study, long-term tracer data from three contrasting catchments in the Scottish Highlands were used for a comparative assessment of interannual variability in TTDs and resulting mean transit times $(\mathrm{MTT}=\alpha \beta)$ inferred by the gamma distribution model. In addition, spatial variation in the long-term average TTDs from these and six additional catchments was also assessed. The temporal analysis showed that the $\beta$ parameter was controlled by precipitation intensities above catchment-specific thresholds. In contrast, the $\alpha$ parameter, which showed little temporal variability and no relationship with precipitation intensity, was found to be closely related to catchment landscape organization, notably the hydrological characteristics of the dominant soils and the drainage density. The relationship between $\beta$ and precipitation intensity was used to express $\beta$ as a time-varying function within the framework of lumped convolution integrals to examine the nonstationarity of TTDs. The resulting time-variant TTDs provided more detailed and potentially useful information about the temporal dynamics and the timing of solute fluxes. It was shown that in the wet, cool climatic conditions of the Scottish Highlands, the transit times from the time-variant TTD were roughly consistent with the variations of MTTs revealed by interannual analysis.

Citation: Hrachowitz, M., C. Soulsby, D. Tetzlaff, I. A. Malcolm, and G. Schoups (2010), Gamma distribution models for transit time estimation in catchments: Physical interpretation of parameters and implications for time-variant transit time assessment, Water Resour. Res., 46, W10536, doi:10.1029/2010WR009148.

\section{Introduction}

[2] Spatial and temporal variations in the hydrological response of catchments are determined by quasi-stationary landscape characteristics (e.g., topography and the nature of the subsurface), as well as nonstationary parameters (e.g., antecedent conditions and precipitation characteristics). Catchment mean transit times (MTT) and the transit time distributions (TTD) around the mean, are commonly used to conceptualize differences in hydrological response through intercatchment comparison [e.g., McGuire et al., 2005; Soulsby et al., 2006; Hrachowitz et al., 2010]. The shape of the TTD reflects the temporal dynamics of the movement of individual water or solute molecules from a given input volume along diverse flow paths from the source to a control point downstream [Kirchner et al., 2001]. Quantitative characterization of TTDs is essential to help understand the

\footnotetext{
${ }^{1}$ Northern Rivers Institute, School of Geosciences, University of Aberdeen, Aberdeen, UK.

${ }^{2}$ Water Resources Section, Faculty of Civil Engineering and Geosciences, Delft University of Technology, Delft, Netherlands.

${ }^{3}$ Freshwater Laboratory, Marine Scotland, Pitlochry, UK.

Copyright 2010 by the American Geophysical Union. 0043-1397/10/2010WR009148
}

integrated nature of catchment-scale flow paths, not only in terms of the physical processes of water movement, but also in terms of contaminant transport and natural flushing rates of diffuse pollutants [Kirchner et al., 2000]. Moreover, they can help to parameterize the heterogeneity of flow paths [Godsey et al., 2010] and estimate the total amount of water storage in catchments [Soulsby et al., 2009]. TTDs are frequently estimated using inverse modeling approaches with lumped convolution integral models and various candidate TTDs. Other methods include the a priori prediction of TTDs, which requires detailed knowledge of flow path distributions and flow velocities [e.g., Lindgren et al., 2004; Darracq et al., 2010].

[3] Over the past three decades, tracer studies in a wide range of geographically diverse catchments have attempted to identify appropriate TTDs [cf. McGuire and McDonnell, 2006]. However, as highlighted by Godsey et al. [2010], the majority of these studies only considered single-parameter exponential distributions [Maloszewski and Zuber, 1982]:

$$
g(\tau)=\tau_{m}^{-1} e^{\left(-\frac{\tau}{\tau_{m}}\right)}
$$

where $\tau$ is the transit time of a subset of particles from the initial input volume and $\tau_{m}$ is the mean transit time. This represents a single linear reservoir, implying that mixing 


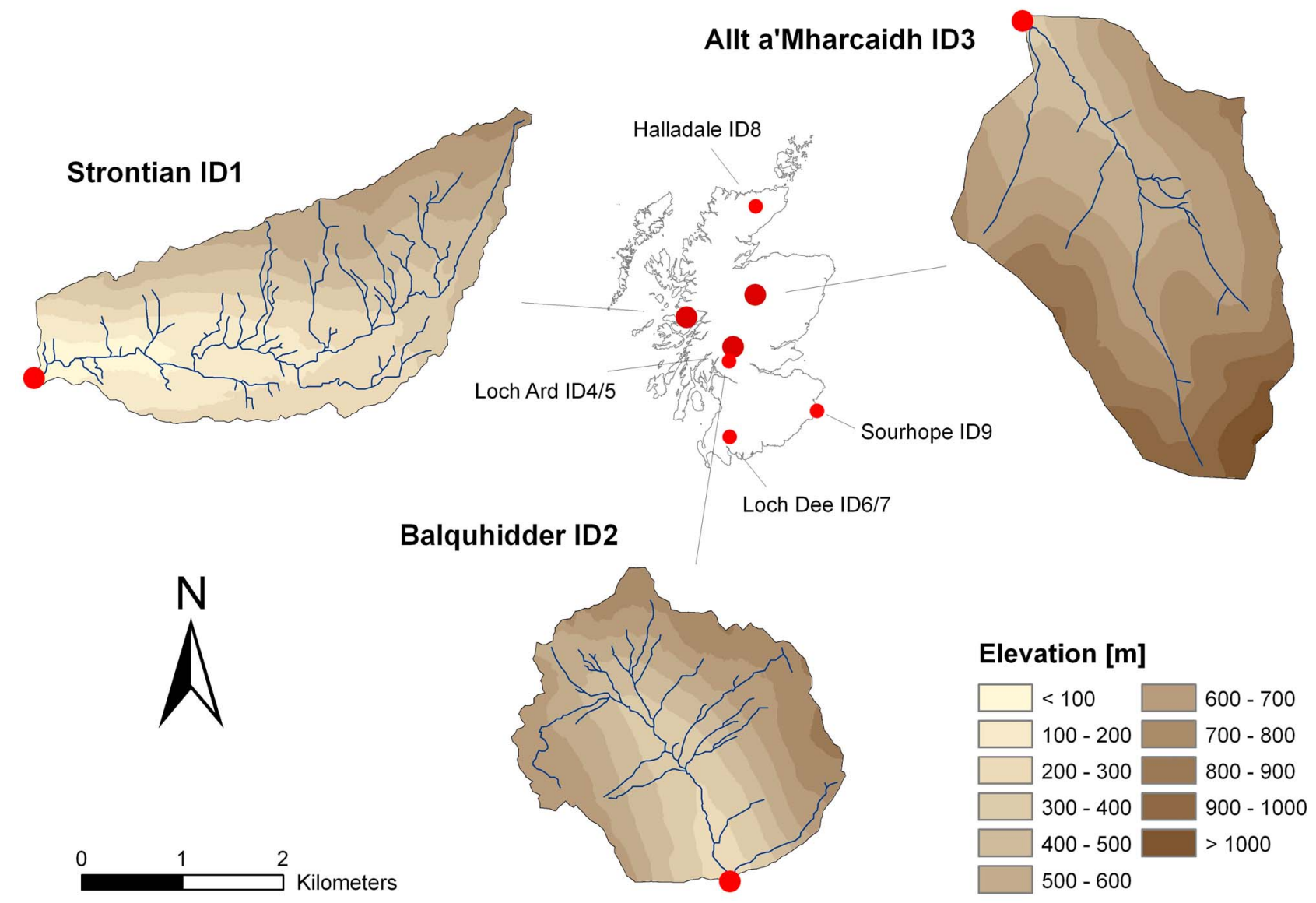

Figure 1. Primary study catchment IDs 1-3 (dark red dots) for detailed interannual analysis and secondary study catchment IDs $4-9$ (light red dots) for comparative spatial analysis.

only occurs at the sampling point, thus no exchange between flow lines is assumed a priori. However, it was shown that this is mathematically equivalent to a wellmixed reservoir [Maloszewski and Zuber, 1996]. The exponential distribution is recognized as an oversimplification for most catchments as it strictly only applies to unconfined, isotropic, granular aquifers. Most catchments, however, are highly heterogeneous and exhibit nonlinear hydrological behavior. As shown by Kirchner et al. [2000], the two parameter gamma distribution is both conceptually and mathematically a more suitable representation of the resulting mixing processes as its higher degree of freedom offers greater flexibility in accounting for different flow path distributions:

$$
g(\tau)=\frac{\tau^{\alpha-1}}{\beta^{\alpha} \Gamma(\alpha)} e^{\left(-\frac{\tau}{\beta}\right)}
$$

where $\alpha$ is the shape parameter, and $\beta$ is the scale parameter and $\tau_{m}=\alpha \beta$. Where $\alpha=1$, the gamma distribution is a close approximation of the exponential distribution. However, it has been shown for a wide range of catchments that $\alpha$ remains well below 1 [Hrachowitz et al., 2009b; Godsey et al., 2010], which reflects pronounced initial tracer peaks and long tails at the sampling point. In other words, for most catchments more solutes are flushed at short time lags and are present at much longer time lags than what would be expected from equation (1). Although exponential distributions can be coupled to produce a similar effect in Two Parallel Linear Reservoir models [Weiler et al., 2003], the gamma distribution avoids the need for a priori definition of flow path partitioning.

[4] In recent studies TTDs, or more specifically MTTs, have been related to a wide range of catchment characteristics in order to identify dominant physical controls. It has been shown that MTTs may be influenced by soil hydrology [Soulsby et al., 2006; Laudon et al., 2007; Tetzlaff et al., 2009a], topographic influences [McGlynn et al., 2003; McGuire et al., 2005], catchment organization [Hrachowitz et al., 2009b] and climate [Tetzlaff et al., 2007b; Hrachowitz et al., 2009a], all of which can affect hydrological flow paths, water storage and associated mixing processes. Most of these studies focused on MTTs rather than on the characteristics of individual parameters of the associated TTDs. Thus, it remains unclear as to which physical interpretations can be ascribed to the $\alpha$ and $\beta$ parameters in the gamma distribution.

[5] Besides the frequent assumption of a well-mixed reservoir, another critical assumption in most tracer studies is the presence of quasi steady state conditions and therefore 
Table 1. Summary of the Study Catchments ${ }^{\mathrm{a}}$

\begin{tabular}{|c|c|c|c|c|c|c|c|c|c|}
\hline ID & Region & Name & $\begin{array}{c}\text { Grid } \\
\text { Reference }\end{array}$ & $\begin{array}{l}\text { Observation } \\
\text { Period }\end{array}$ & $\begin{array}{c}\text { Average } \\
\text { Annual } \\
\text { Precipitation } \\
\left(\mathrm{mm} \mathrm{yr}^{-1}\right)\end{array}$ & $\begin{array}{c}\text { Area } \\
\left(\mathrm{km}^{2}\right)\end{array}$ & $\begin{array}{c}\text { Elevation } \\
\text { Range } \\
\text { (m) }\end{array}$ & $\begin{array}{l}\text { Proportion } \\
\text { Responsive } \\
\text { Soil Cover }\end{array}$ & $\begin{array}{c}\text { Drainage } \\
\text { Density } \\
\left(\mathrm{km} \mathrm{km}^{-2}\right)\end{array}$ \\
\hline 1 & Strontian & Allt Coire nan Con & NM 793688 & $1986-2003$ & 2690 & 8.0 & $18-755$ & 0.79 & 3.8 \\
\hline 2 & Balquhidder & Kirkton & NN 533220 & $1987-2000$ & 2720 & 6.8 & $248-849$ & 0.26 & 2.8 \\
\hline 3 & Allt a'Mharcaidh & Site 1 & NH 882043 & 1990-2006 & 1100 & 9.6 & $330-1022$ & 0.35 & 1.3 \\
\hline 4 & Loch Ard & Burn 2 & NN 388042 & $1988-2002$ & 2200 & 4.0 & 154-971 & 0.92 & 3.8 \\
\hline 5 & Loch Ard & Burn 11 & NS 470988 & 1988-2002 & 2200 & 1.4 & $99-282$ & 1.00 & 2.2 \\
\hline 6 & Loch Dee & Green Burn & NX 481791 & 1998-2001 & 3300 & 2.6 & $230-550$ & 0.92 & 1.9 \\
\hline 7 & Loch Dee & White Laggan & NX 468781 & 1998-2001 & 3300 & 5.8 & $229-668$ & 0.85 & 2.2 \\
\hline 8 & Halladale & Allt a'Bhealaich & NC 892433 & 1993-1994 & 1300 & 3.7 & $128-338$ & 0.76 & 1.9 \\
\hline 9 & Sourhope & Rowantree Burn & NT 860204 & 1994-2003 & 880 & 0.4 & $297-508$ & 0.00 & 1.8 \\
\hline
\end{tabular}

${ }^{\mathrm{a}}$ The primary catchments (IDs 1-3) were used in interannual analysis and the secondary catchments (IDs 4-9) were additionally used in spatial analysis.

the application of time-invariant transit time distributions [cf. McGuire and McDonnell, 2006] to characterize the hydrological regime over the entire observation period. The limitations of this assumption have long been recognized [Maloszewski and Zuber, 1982]. As a result alternative methods to overcome this problem have been suggested, such as replacing time by flow-corrected time [Rodhe et al., 1996] or using stochastically derived time-variant transit time distributions [Turner et al., 1987]. Indeed, in a recent review, McGuire and McDonnell [2006] suggested that future studies should explore the possibility of expressing TTDs as function of some metric of catchment wetness. Despite this, it has been shown that for many applications the steady state assumption gave functionally equivalent results, i.e., the average transit time for variable conditions was very close to that found from the steady state approach [Maloszewski and Zuber, 1996], in particular when using flow-corrected time [Fiori and Russo, 2008]. Nevertheless, ignoring nonstationarity and using time-invariant TTDs remains theoretically unsatisfactory and can potentially result in substantial misrepresentation of the timing and magnitude of peak solute fluxes as well as giving no insight into the temporal variability of transit times, even though such variability has been demonstrated [e.g., Botter et al., 2008; Hrachowitz et al., 2009a].

[6] A key constraint on exploring time-variant TTDs is the lack of adequate data sets. Long-term tracer data for periods of over a decade offer the opportunity to carry out "moving window" analysis on tracer input-output relationships over periods with markedly different climatic characteristics [Hrachowitz et al., 2009a]. Where such data are available for catchments with different landscape properties and/or in different climatic provinces, intercatchment comparison can facilitate analysis of how the TTD varies both in time and space. This creates the further opportunity to test the utility of the gamma distribution and systematically examine how the parameters vary in different catchments with different landscape characteristics, and under varying climatic conditions as advocated by Beven [2010] and McDonnell et al. [2010]. This paper utilizes such long-term data for contrasting catchments in the Scottish Highlands and explores possible physical interpretations of the gamma distribution parameters. The paper tests the following hypotheses: (1) the $\alpha$ and $\beta$ parameters of the gamma distribution systematically vary with spatial variability in landscape characteristics at the catchment scale, (2) the $\alpha$ and $\beta$ parameters vary interannually and intra-annually in catchments as a result of variable meteorologic and antecedent conditions, and (3) such physical controls on the parameters $\alpha$ and $\beta$ can be used to generate time-variant transit time distributions for individual catchments.

\section{Study Sites}

[7] Interannual analysis of TTDs was based on three montane catchments in the Scottish Highlands (Figure 1). The contrasting regimes of these three primary sites are illustrated by the catchment characteristics (Table 1) and by flow duration curves (Figure 2); these highlight the flashy streamflow response at Strontian (ID 1) and Balquhidder (ID 2) and a more subdued flow regime in the Allt a'Mharcaidh (ID 3). The three catchments range from 6.8 to $9.6 \mathrm{~km}^{2}$ in area and vary in soil cover, underlying geology, land use and climate. The Strontian catchment spans an altitudinal range of $20-760 \mathrm{~m}$ and is located in the maritime northwest of Scotland, with average annual precipitation of about $2700 \mathrm{~mm}$ and highest mean annual temperatures of $7.2^{\circ} \mathrm{C}$. The bedrock comprises schist and gneiss and is mainly overlain by hydrologically responsive histosols (peats and peaty gleys) [Ferrier and Harriman, 1990]. Land cover comprises 50\% coniferous forest (Picea sitchensis) and $50 \%$ heather moorland (Calluna vulgaris). The Kirkton

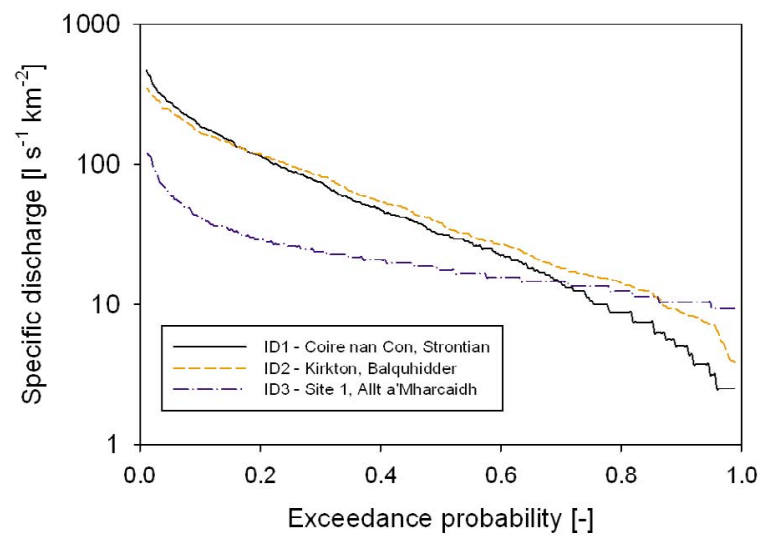

Figure 2. Median annual flow duration curves for the primary catchment IDs 1-3 based on the individual observation periods. 
catchment at Balquhidder, lies between 250 and $850 \mathrm{~m}$, shows similar high average annual precipitation of about $2700 \mathrm{~mm}$ and a mean annual temperature of $5.9^{\circ} \mathrm{C}$. The catchment is dominated by more freely draining humus iron podzols and brown forest soils, with minor areas of shallow peats and peaty gleys [Johnson, 1991]. These overlie schist and drift material of variable depth [Stott, 1997]. While the lower part of the catchment is forested (Picea sitchensis), heather moorland dominates higher areas (Calluna vulgaris). The Allt a'Mharcaidh is located in the Cairngorm Mountains at elevations between 330 and $1100 \mathrm{~m}$, and has a subarctic climate with relatively low average annual precipitation of about $1100 \mathrm{~mm}$ and mean annual temperatures of $5.1^{\circ} \mathrm{C}$. The catchment is underlain by granite with deep and coarse drift deposits of up to $10 \mathrm{~m}$ in depth [Soulsby et al., 1998]. Freely draining humus-iron podzols and alpine podzols dominate the steep slopes, while the valley bottoms are covered by deep peats [Soulsby et al., 2000]. Land cover includes alpine heath in higher regions and $<10 \%$ mixed natural forest (Pinus sylvestris, Betula spp.) on the lower slopes.

[8] Six secondary catchments (IDs 4-9) from contrasting regions across Scotland were used for comparative spatial analysis (Figure 1 and Table 1). Briefly, the catchments exhibit marked differences in climate (average annual precipitation 800-3300 mm), topography (mean elevation 180$450 \mathrm{~m}$ ), as well as soil types. Detailed descriptions can be found by Hrachowitz et al. [2009b]. Note that in the following, soils are grouped into "hydrologically responsive" soils, which are those generating rapid storm runoff, mainly by overland flow processes, and encompass histosols and regosols. Conversely, soils dominated by deeper subsurface flow processes, such as podzols and brown forest soils, are grouped as "freely draining" [cf. Tetzlaff et al., 2007a]. This generally corresponds to the UK HOST (Hydrology of Soil Type) soil classification [Boorman et al., 1995].

\section{Data and Methods}

\subsection{Hydrological and Hydrochemical Data}

[9] At each site daily streamflow and precipitation data were available for 13-17 years for the primary sites (IDs 1-3) and between 2 to 14 years for the secondary sites (IDs 4-9) (Table 1). Precipitation gauges were located within $1 \mathrm{~km}$ of the catchment outlet, where stream gauges were operated by the Scottish Environment Protection Agency. Precipitation was sampled at weekly to fortnightly intervals using open funnel bulk deposition samplers. Stream water dip samples were taken on the same dates as the precipitation samples at the catchment outlets (Figure 1). All water samples were filtered through a $0.45 \mu \mathrm{m}$ polycarbonate membrane filter and subsequently analyzed for $\mathrm{Cl}^{-}$concentrations by ion chromatography (Dionex DX100/DX120).

\subsection{Transit Time Estimation}

[10] In the absence of gross anthropogenic disturbances in the relatively natural upland catchments investigated in this study, $\mathrm{Cl}^{-}$was assumed to act as a conservative natural tracer [Neal et al., 1988], which is supported by Kirchner et al. [2010], who demonstrated similar damping dynamics between input and output for both $\mathrm{Cl}^{-}$and $\delta^{18} \mathrm{O}$ as hydro- logical tracers. Reflecting the marine derived salts which tend to dominate the ionic composition of precipitation [Neal and Kirchner, 2000], $\mathrm{Cl}^{-}$concentrations in precipitation exhibit a pronounced seasonal cycle and can therefore be used to estimate TTDs [e.g., Kirchner et al., 2000; Shaw et al., 2008; Hrachowitz et al., 2009a, 2009b].

[11] As the stream tracer response depends on the actual tracer mass flux, rather than on concentrations alone, the mass weighted input was used to estimate time-invariant TTDs with the lumped convolution integral method [Stewart and McDonnell, 1991; Weiler et al., 2003]:

$$
c_{\text {out }}(t)=\frac{\int_{0}^{\infty} g(\tau) w(t-\tau) c_{\text {in }}(t-\tau) d \tau}{\int_{0}^{\infty} g(\tau) w(t-\tau) d \tau}
$$

where $\tau$ is the transit time, $t$ is the time of exit from the system and $(t-\tau)$ represents the time of entry into the system. Thus, the $\mathrm{Cl}^{-}$output concentration $c_{\text {out }}(t)$ in the stream at any time $\mathrm{t}$ equals the combined $\mathrm{Cl}^{-}$input concentrations $c_{i n}(t-\tau)$ from any time in the past weighted by the TTD or transfer function $g(\tau)$, which in this paper is the gamma distribution (equation (2)), and the mass weighting factor, i.e., precipitation amount, $w(t-\tau)$.

[12] To account for deficits in stream water $\mathrm{Cl}^{-}$fluxes [Neal et al., 1988], likely to be caused by $\mathrm{Cl}^{-}$disequilibria [Guan et al., 2010], as well as by dry and occult deposition, and depending on vegetation, topography, climatic conditions and land use history, lumped adjustment factors were applied to maintain the $\mathrm{Cl}^{-}$balance [Dunn and Bacon, 2008]. Although such lumped adjustment factors should be treated with caution in regions with marked climatic seasonality, the wet Scottish climate, where precipitation is relatively high and evenly distributed throughout the year makes their use reasonable [Tetzlaff et al., 2007b]. The factors applied range from about 1.0 to 2.1 and are similar to those reported by others: 1.55 for a moorland catchment [Dunn and Bacon, 2008], 1.9-2.8 for forested catchments [Tetzlaff et al., 2007b; Shaw et al., 2008].

[13] The use of the convolution integral method implies that the stream response reflects the combined tracer inputs of the past. To limit adverse effects of unknown inputs prior to the start of observations and significant tracer mass imbalance at the beginning of the calibration period (i.e., a tracer deficit in the system) for catchments with long TTDs, a "warm-up" period of 50 years was used. This period was derived from a combination of 46 years of looped data from the end of the observation period [cf. Hrachowitz et al., 2009a] followed by an additional 4 years which were the first 4 years of the original data set. Thus, these 4 years were the final years used to condition the model prior to the retained observation periods shown in Figure 3. For the catchments with observation periods $<4$ years (Table 1 ), only the first year of the observation period was used in the "warmup" and excluded from the evaluation data. The data set was then looped to a total of 49 years.

[14] For assessing the influence of climatic conditions on the $\alpha$ and $\beta$ parameters in the gamma distribution, TTDs for the each year in the retained observation period (i.e., the total 


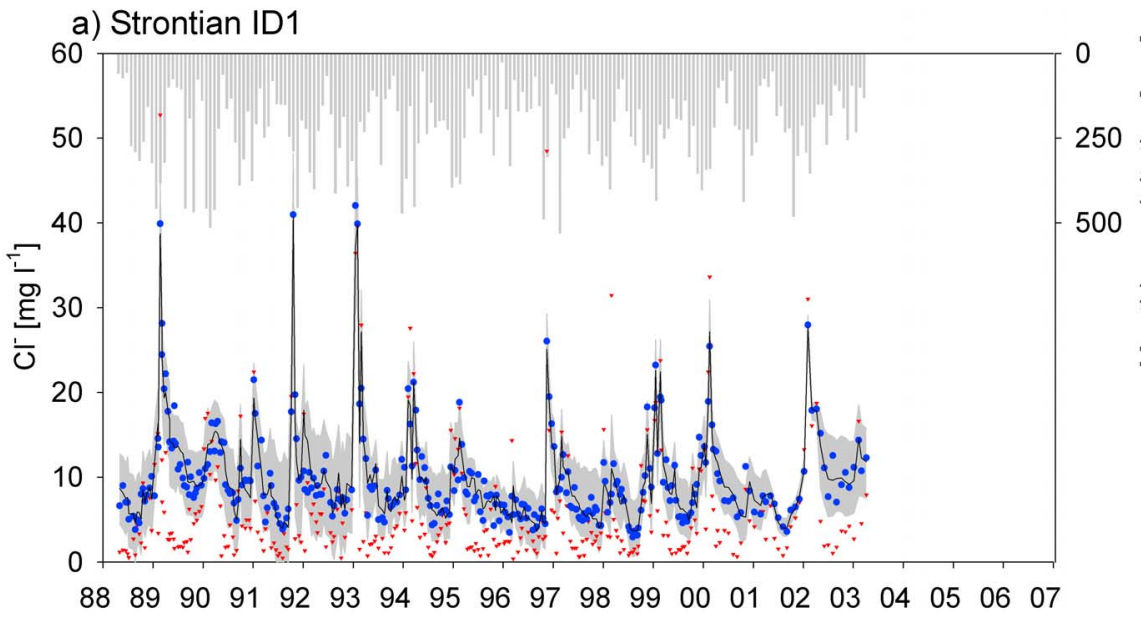

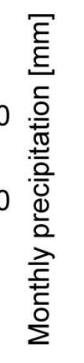

b) Balquhidder ID2

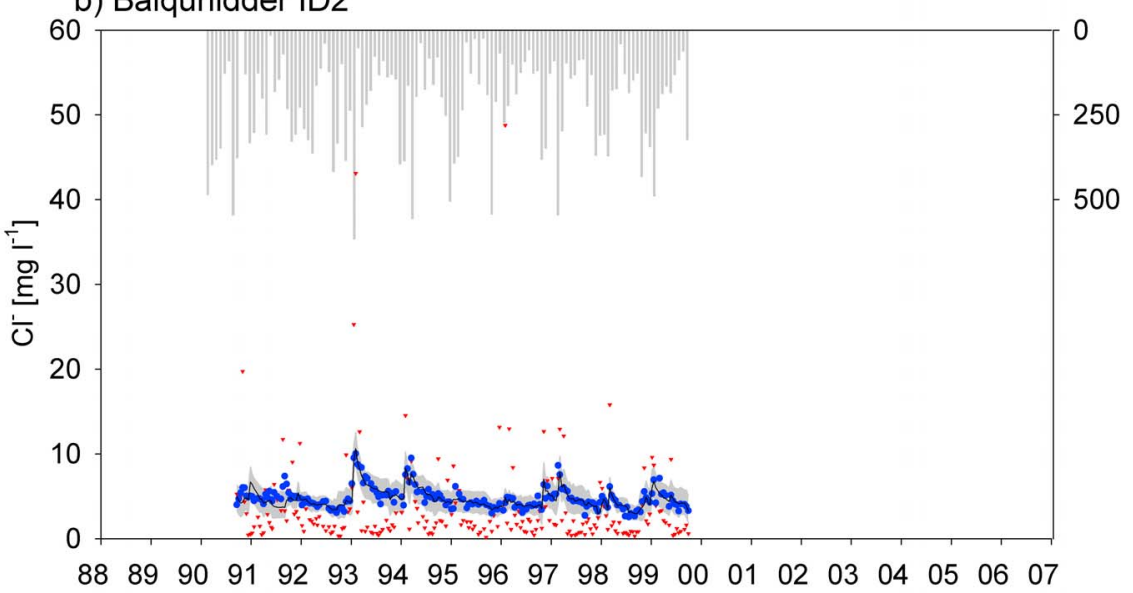

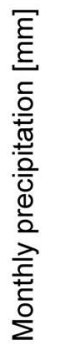

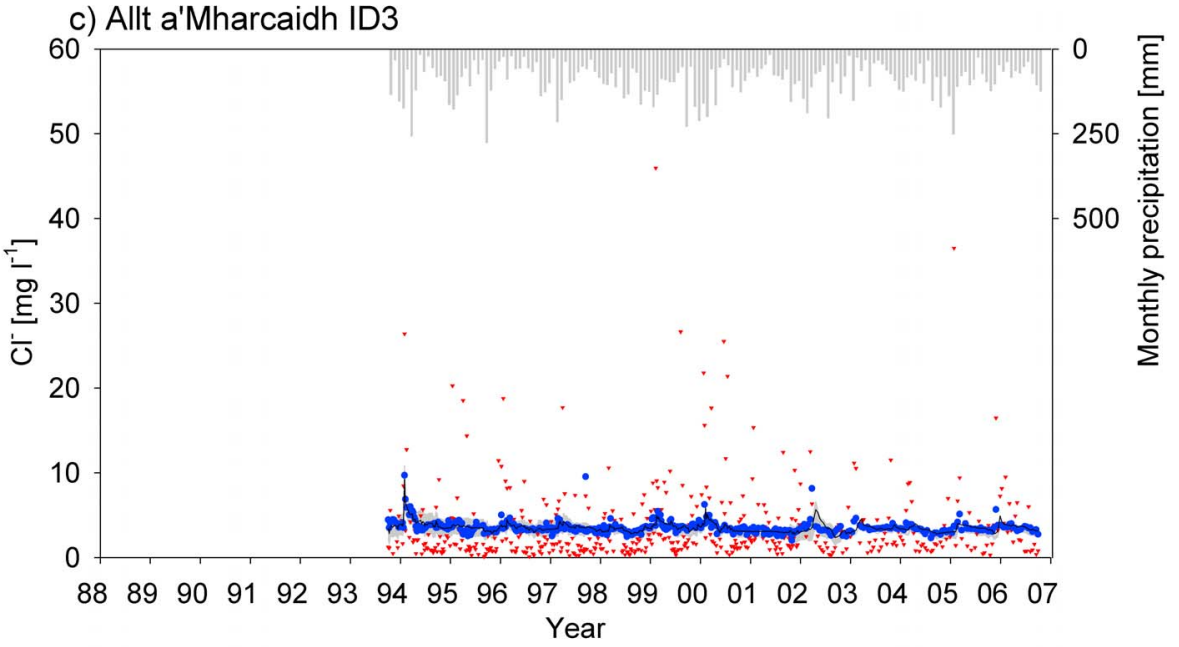

Figure 3. Time series of precipitation and $\mathrm{Cl}^{-}$input and output concentrations at (a) Coire nan Con (Strontian, ID 1), (b) Kirkton (Balquhidder, ID 2), and (c) site 1 (Allt a'Mharcaidh, ID 3). The grey bars show the monthly precipitation, the inverted triangles are observed $\mathrm{Cl}^{-}$concentrations in precipitation, blue dots are observed $\mathrm{Cl}^{-}$concentrations in the stream water, the solid black line represents the modeled best fit models, and the shaded area is the $95 \%$ uncertainty interval of the modeled $\mathrm{Cl}^{-}$stream concentration using the gamma distribution for each individual year of the retained observation periods. 
observation period excluding the first 4 years which were included in the "warm-up" period) were estimated for the three primary catchments (IDs 1-3) in a detailed interannual analysis. Furthermore, to facilitate spatial comparison and to explore the influence of quasi-stationary catchment characteristics on $\alpha$ and $\beta$, the time-invariant TTD over the entire retained observation period was derived for each catchment (IDs 1-9).

\subsection{Parameter Estimation}

[15] The parameters $\alpha$ and $\beta$ of the TTD are inferred from observed tracer data using a Bayesian approach:

$$
p(\theta, \sigma \mid Y) \propto p(Y \mid \theta, \sigma) p(\theta, \sigma)
$$

where $p(\theta, \sigma \mid Y)$ is the posterior distribution of the parameters $\theta$ and the standard deviation $\sigma$ of the error model, $p(\theta, \sigma)$ are the prior distributions of $\theta$ and $\sigma$, assumed to be uniform $(0<\alpha<1.5$ and $0<\beta<30000)$, and $p(Y \mid \theta, \sigma)$ is the likelihood function which can be expressed as

$$
p(Y \mid \theta, \sigma)=\prod_{i=1}^{N_{y}} N\left(\xi_{i}(\theta, Y) \mid 0, \sigma^{2}\right)
$$

where $N\left(\xi \mid \mu, \sigma^{2}\right)$ is the distribution of the residual errors $\xi$, with mean $\mu$ and variance $\sigma^{2}$, assuming that the errors are independent and identically distributed according to a Gaussian density. Posterior diagnostic plots (not shown) indicated that these assumptions were applicable in the cases studied here.

[16] The best parameter set was obtained from maximizing the log likelihood function and parameter uncertainty was estimated by sampling parameter sets from the uniform prior parameter space using a Markov chain Monte Carlo (MCMC) simulation. The MCMC algorithm used in this paper is the DREAM-ZS algorithm, designed by Vrugt et al. [2009] and developed further by Schoups and Vrugt [2010]. The sampling strategy used 3 parallel chains and the first 3000 model runs were used as warm-up period. In general, convergence, as measured by the Gelman-Rubin statistic, was reached after 10,000 model runs.

\subsection{Controls on Parameters $\alpha$ and $\boldsymbol{\beta}$}

[17] Several precipitation metrics were used to assess the potential influence of climatic controls on TTDs in general [cf. Weiler and McDonnell, 2004; Hrachowitz et al., 2009a] and on the parameters $\alpha$ and $\beta$ of the gamma distribution in particular. Previous studies suggested that TTDs are more strongly influenced by precipitation intensity than by precipitation amounts [Hrachowitz et al., 2009b]. Thus, for the interannual analysis of the primary catchments (IDs 1-3), the metrics not only included annual precipitation totals but also different measures of precipitation intensity (Table 2). These included the annual amounts of precipitation falling on days with precipitation above the thresholds $1,5,10,15$, 20,25 , and $30 \mathrm{~mm}\left(\mathrm{P}_{1 \mathrm{~mm}}, \ldots, \mathrm{P}_{30 \mathrm{~mm}}\right)$. Furthermore, the number of days per year with precipitation above these thresholds $\left(\mathrm{N}_{1 \mathrm{~mm}}, \ldots, \mathrm{N}_{30 \mathrm{~mm}}\right)$ was considered, as were the daily precipitation amounts with $5,10, \ldots, 50 \%$ probability of exceedance $\left(\mathrm{P}_{5}, \ldots, \mathrm{P}_{50}\right)$. Note that in the following, the term precipitation intensity is used to label the above sug- gested precipitation metrics. To account for catchment wetness prior to the individual years of the interannual analysis, the respective precipitation metrics used in the regression analysis were weighed exponentially backward. The actual year of interest was thus assigned a weight of 1 while earlier years were assigned reduced weights according to an exponential distribution with a decay parameter $\tau_{w}=1$ year.

[18] The controls on TTDs were identified using Pearson's correlation coefficient and principal component analysis (PCA). Both analyses were done using weighed covariances to account for varying annual performance levels in terms of Nash-Sutcliffe efficiency (NSE) (see section 4):

$$
\operatorname{cov}(x, y ; w)=\frac{\sum_{i=1}^{N} w_{i}\left(x_{i}-m(x ; w)\right)\left(y_{i}-m(y ; w)\right)}{\sum_{i=1}^{N} w_{i}}
$$

where $N$ is the sample size, $x$ and $y$ are the data vectors, $w$ is the weight, here assumed to be the NSE and $m$ is the weighed mean:

$$
m(x ; w)=\frac{\sum_{i=1}^{N} w_{i} x_{i}}{\sum_{i=1}^{N} w_{i}}, \quad m(y ; w)=\frac{\sum_{i=1}^{N} w_{i} y_{i}}{\sum_{i=1}^{N} w_{i}}
$$

Uncertainty in the correlation coefficients caused by uncertainty of parameters $\alpha$ and $\beta$ was estimated by sampling from he posterior parameter distributions (10,000 Monte Carlo realizations) and computing the respective weighted correlation coefficient for each realization, resulting in a correlation coefficient distribution.

\subsection{Time-Variant Transit Time Estimation}

[19] To incorporate relationships between precipitation metrics and transit times, in order to derive time-variant TTDs, the gamma transfer function $h(\tau)$ was expressed as

$$
h(\tau, t)=f\left(\alpha, \beta, \sum_{i=0}^{t} P_{j}\left(t_{i}, \tau_{w}\right)\right)
$$

where $P_{j}$ is the value of the chosen precipitation metric $\mathrm{j}$. Here $\sum P_{j}\left(t_{i}, \tau_{w}\right)$ is the exponentially backward weighted sum of precipitation falling on days with precipitation totals exceeding $\mathrm{x} \mathrm{mm}\left(\mathrm{P}_{\mathrm{xmm}}\right)$ prior to $t_{i}$. Incorporation of $P_{j}$, exponentially weighted backward in time, using weighting exponent $\tau_{w}$, facilitated analysis of days with $P_{j}=0$ and at the same time took into account the decreasing influence of antecedent precipitation. Thus, the composite time-variant $\mathrm{TTD}_{\mathrm{var}}$ of an isolated, instantaneous input signal entering the system at $(t-\tau)$ consists of a combination of individual TTDs, which can vary at every time step i according to $P_{j}\left(t_{i}\right.$, $\left.\tau_{w}\right)$. The initial value of $\mathrm{TTD}_{\mathrm{var}}$ depends on $P_{j}\left(t_{i}, \tau_{w}\right)$ up to the date of entry $t_{0}=(t-\tau)$. For each subsequent time step $i$, an individual TTD for the original signal entering at $(t-\tau)$ is obtained from $P_{j}\left(t_{i}, \tau_{w}\right)$ at $t_{i}$ and rescaled so that the cumulative density function of the combined time-variant $\mathrm{TTD}_{\text {var }}$ equals unity. Due to computationally intensive 


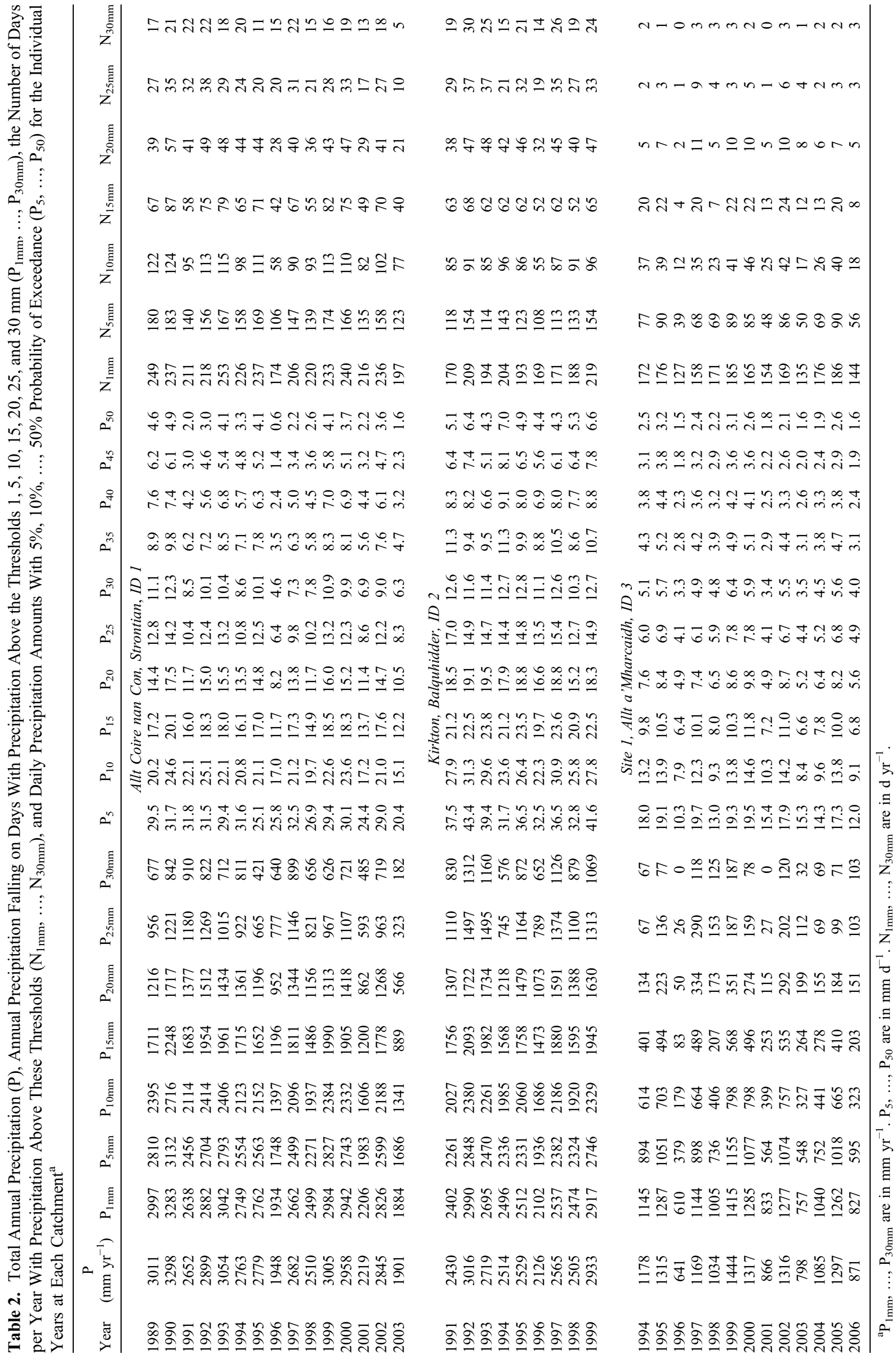


nature of this approach $(\sim 150 \mathrm{~h}$ for ID 1$)$, this was only applied to the Strontian site (ID 1) as an example.

[20] Two criteria, $R_{a j j}^{2}$ and the Bayesian Information Criterion (BIC), both accounting for the number of parameters in the model, were used to assess the performance of the time-variant transit time model compared to the timeinvariant model:

$$
R_{a d j}^{2}=1-\left(\frac{n-1}{n-p}\right) \frac{S S E}{S S T}
$$

where $S S E$ is the sum of squared errors and $S S T$ is the total sum of squares, $n$ is the number of observations and $p$ is the number of regression parameters [cf. Ahmadi-Nedushan et al., 2007]:

$$
B I C=n \ln \left(\frac{S S E}{n}\right)+p \ln (n)
$$

Both, $\mathrm{R}_{\mathrm{adj}}^{2}$ and BIC are performance measures that balance model fit and model parsimony. The best models are those with the highest $\mathrm{R}_{\mathrm{adj}}^{2}$ and the lowest BIC.

\section{Results and Discussion}

\subsection{Time-Invariant Transit Time Estimation}

[21] For the three primary catchments (IDs 1-3), the timeinvariant TTDs were initially estimated for each individual year of the retained observation period (Table 3). The contrasting nature of the response in the three catchments is illustrated by Figure 3 which mirrors the flow duration curves shown in Figure 2. The tracer stream response in the Strontian catchment (ID 1, Figure 3a) is very marked and only weakly damped compared to the input signal. In most years, the modeled stream tracer signal resulted in a good fit with NSE of up to 0.99 . This catchment generally showed the lowest values for both parameters $\alpha$ and $\beta$. The MTTs resulting from the maximum likelihood parameter sets for the individual years ranged from 65 to 1417 days. The tracer response of the Balquhidder catchment (ID 2, Figure 3b) showed a more subdued pattern. The modeled tracer stream signal showed reasonable fits for the majority of years with NSE of up to 0.87 . Parameters $\alpha$ and $\beta$ showed intermediate values resulting in MTTs derived from maximum likelihood parameters between 252 and 2627 days. The Allt a'Mharcaidh catchment (ID 3, Figure 3c) shows a much more attenuated $\mathrm{Cl}^{-}$stream signal, resulting in generally poorer model performances. Although NSE reached 0.83, four years showed NSE well below 0.40. The maximum likelihood estimates of $\alpha$ and $\beta$, were in general the highest of the three catchments. The resulting MTTs were found to be between 854 and 6174 days.

[22] The time-invariant TTDs over the entire retained observation periods were also estimated for all study catchments (IDs 1-9). The results are summarized in Table 3. Briefly, the results show varying levels of fit, i.e., NSE = 0.18-0.86, and a wide range of MTTs and parameter values highlighting the contrasting nature of the catchment responses. However, in general, the values for the secondary catchments fall within the range of the three primary catchments.

\subsection{Temporal Influences on the $\alpha$ and $\beta$ Parameters}

[23] The influence of climatic (i.e., nonstationary) conditions on $\alpha$ and $\beta$ was assessed for the primary catchments (IDs 1-3) by correlating the interannual sets of the logtransformed $\alpha$ and $\beta$ values (Table 3 ) with the respective logtransformed precipitation metrics exponentially weighted backward in time (Table 2). The results are summarized in Table 4. In general, there were no statistically significant relationships $(\mathrm{p}>0.10)$ between parameter $\alpha$ and any of the precipitation metrics. On the other hand, $\beta$ exhibits significant inverse relationships of varying strengths with several precipitation metrics, depending on the catchment. For the Strontian catchment (ID 1), $\beta$ showed the best relationships with $\mathrm{P}_{5}(\mathrm{r}=-0.73)$, i.e., the amount of daily precipitation with $5 \%$ exceedance probability, as well as with $\mathrm{P}_{30 \mathrm{~mm}}$, i.e., the amount of annual precipitation falling on days with at least $30 \mathrm{~mm}$ of precipitation, and correspondingly with the $\mathrm{N}_{30 \mathrm{~mm}}$, i.e., the number of days with precipitation above $30 \mathrm{~mm}$. The 90th percentiles of the correlation coefficients for these three relationships are significant, i.e., the $\mathrm{p}$ value for the given relationships is lower than 0.1 for at least $90 \%$ of the correlations obtained from random samples from the posterior parameter distributions. In the Balquhidder catchment (ID 2), the precipitation indices most strongly affecting $\beta$ are $\mathrm{P}_{45}(\mathrm{r}=-0.86)$ and correspondingly $\mathrm{N}_{5 \mathrm{~mm}}$. However, no significant correlation between $\beta$ and $\mathrm{P}_{\mathrm{xmm}}$ was found in the Balquhidder catchment. Although $\mathrm{p}<0.10$ for the 90th percentile of $\mathrm{P}_{45}, \mathrm{p}=0.15$ for the 90 th percentile of $\mathrm{N}_{5 \mathrm{~mm}}$, resulting in only $84 \%$ of the correlations obtained from samples from the posterior distribution being significant $(\mathrm{p}<0.10) . \mathrm{P}_{5 \mathrm{~mm}}(\mathrm{r}=-0.66), \mathrm{N}_{5 \mathrm{~mm}}$ and correspondingly $\mathrm{P}_{15}$ exhibited the strongest correlations in the Allt a'Mharcaidh catchment (ID 3), with the 90th percentile of $r$ for $P_{5 \mathrm{~mm}}$ and $\mathrm{N}_{5 \mathrm{~mm}}$ being significant $(\mathrm{p}<0.10)$. One selected relationship between precipitation metric and the maximum like likelihood estimates of $\alpha$ and $\beta$ for each catchment is shown in Figure 4, together with the distribution of the correlation coefficients $r$ of the relationships involving $\beta$ for parameters sampled from the respective annual posterior distributions of $\beta$.

[24] Although, the absolute values of precipitation intensity which show the strongest correlations with $\beta$ vary between the catchments, the data suggest that, in general, precipitation intensities above certain catchment-specific thresholds are influencing $\beta$. As $\alpha$ seems to be uncorrelated to changing interannual conditions, $\beta$ is thus also effectively controlling interannual variability in the MTT estimates for the individual catchments [cf. Hrachowitz et al., 2009a]. It can thus be assumed that the absolute level of the precipitation intensity threshold influencing $\beta$ in a given catchment can potentially be seen as an indicator of threshold conditions which affect substantial changes in catchment response and flow paths and which reflect the soil types and landscape organization of individual sites.

\subsection{Spatial Influences on the $\alpha$ and $\beta$ Parameters}

[25] While influence of precipitation intensity on $\beta$ is evident (Table 4), it can be seen that $\alpha$ is not influenced by precipitation intensity; it is rather changing from catchment to catchment. According to an ANOVA, the median $\alpha$ values of the individual catchments are significantly different from 
Table 3. Nash-Sutcliffe Efficiencies (NSEs), Parameters, and Resulting MTTs for Model Runs Over Each Individual Year in the Interannual Analysis for Catchment IDs 1-3 and in the Spatial Analysis for Model Runs Over the Period 1994-1997 for Catchment IDs $1-9^{\text {a }}$

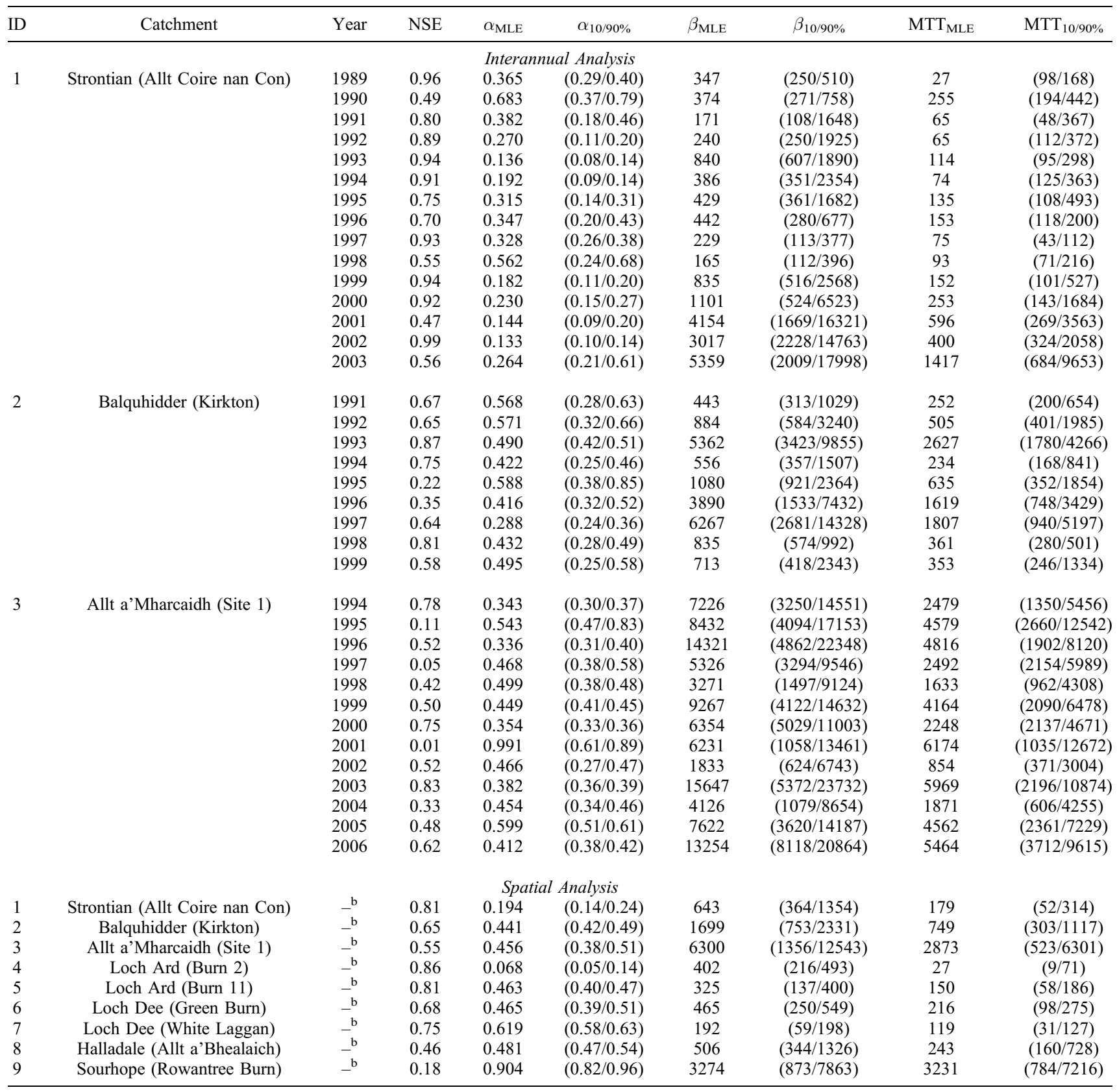

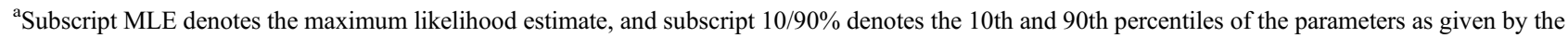
posterior parameter distributions.

${ }^{\mathrm{b}}$ Entire retained observation period.

each other $(\mathrm{p}<0.05)$. The Strontian catchment (ID 1), with very low values of $\alpha$, is characterized by a high percentage of responsive soils and a high drainage density (Table 1). Thus, the combination of surface and shallow subsurface preferential flow paths in near-saturated soils overlying relatively impermeable bedrock and being well connected to the stream network is consistent with a highly nonlinear response, since such flow paths are activated by relatively high intensity rainfalls (Table 3 ). This allows water to be rapidly turned over during and some time after the precipitation event, before the system gradually switches back to draining the lowpermeability soil matrix and fractured bedrock at much lower rates. On the other hand, the highest values of $\alpha$ were found for the Allt a'Mharcaidh catchment (ID 3), which is characterized by more freely draining soils, overlying coarse drift deposits and fractured granite bedrock [Soulsby et al., 1998]. A tracer stream response somewhat closer to linear can therefore be expected. These results are thus consistent with the suggestion that $\alpha$ is an indicator for the structure of a given catchment, as has been hypothesized earlier [Godsey et al., 


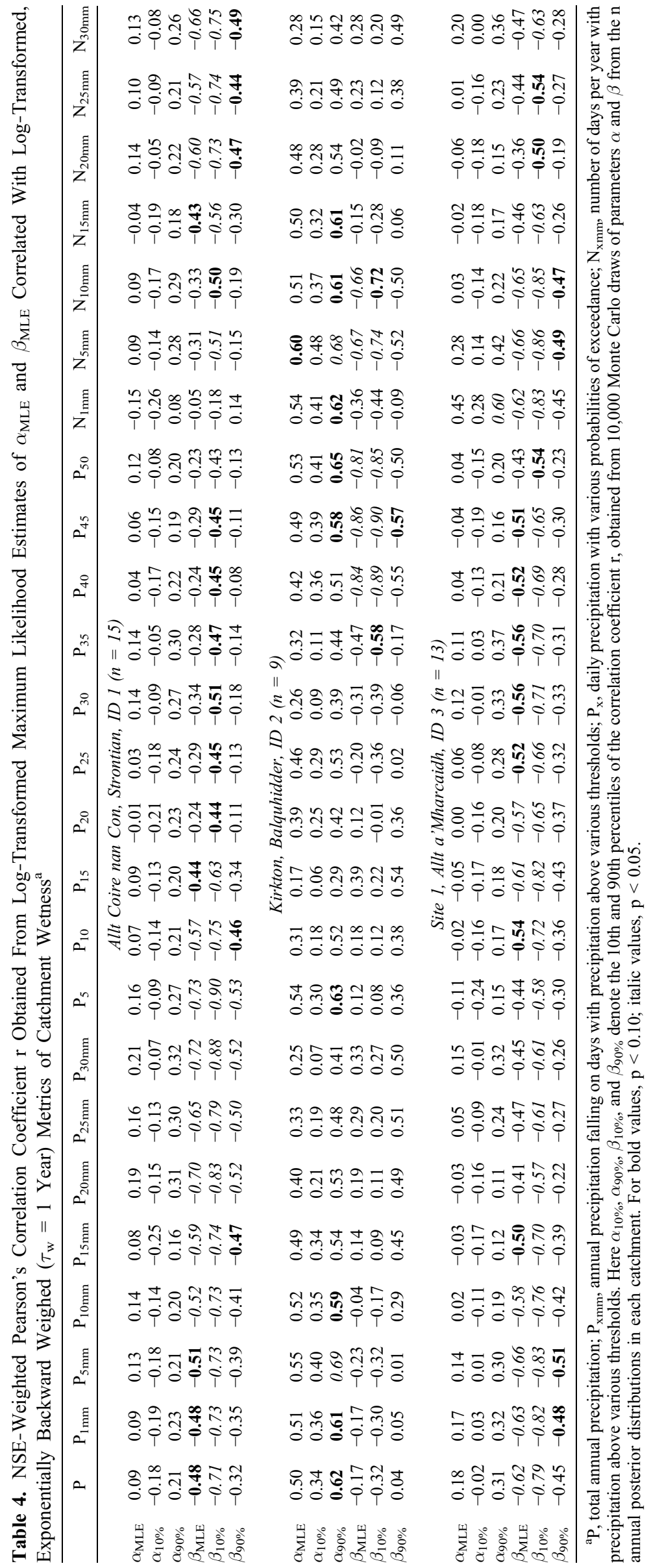



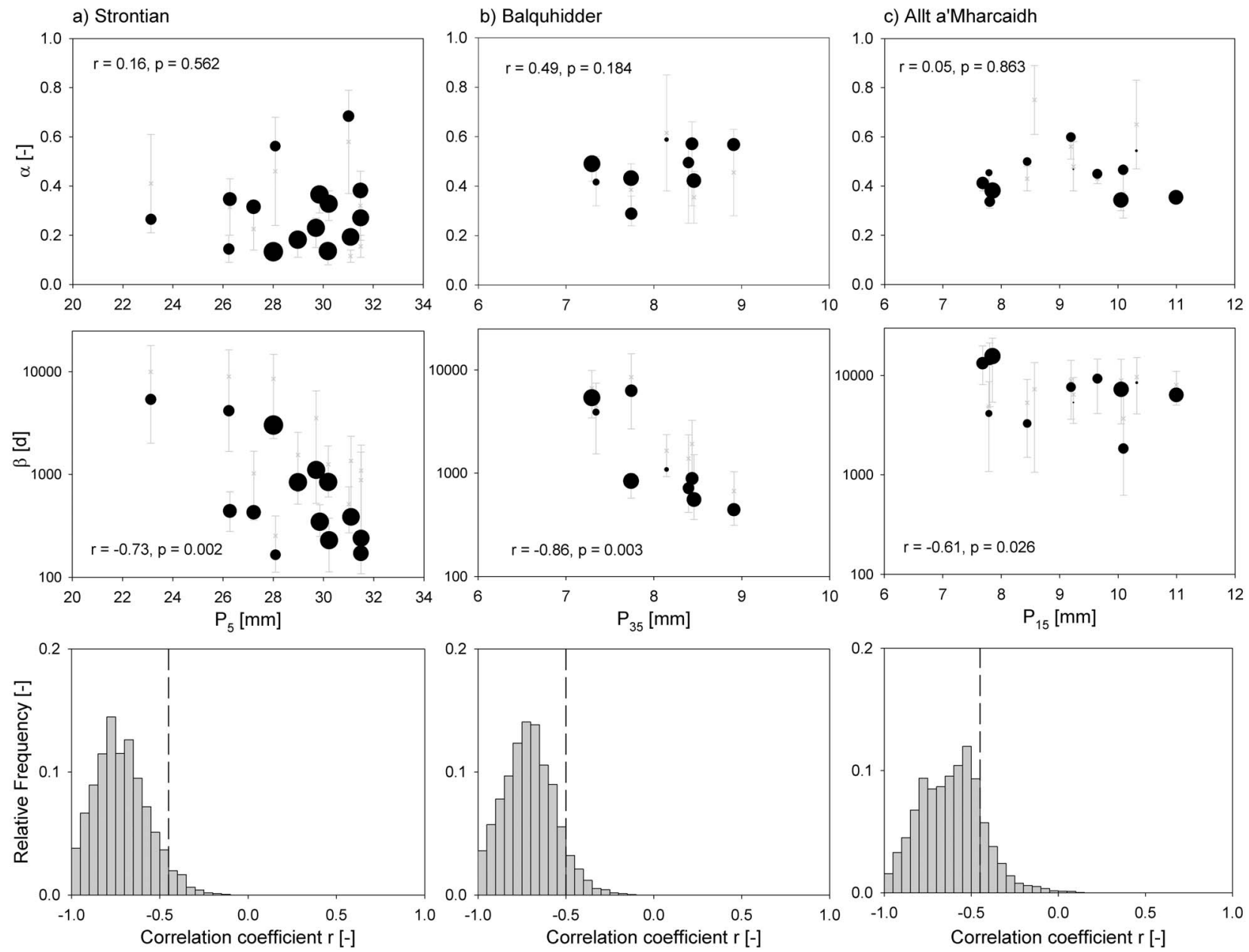

Figure 4. The top and middle rows show $\alpha$ and $\beta$ against the most characteristic $\mathrm{P}_{\mathrm{x}}$ for each of the three primary catchments: (a) ID 1, (b) ID 2, and (c) ID 3. The black dots are the maximum likelihood estimates for $\alpha$ and $\beta$ for each individual year. Their size represents their NSE and thus their respective weight in the relationship. The grey crosses show the median value for $\alpha$ and $\beta$, while the error bars indicate $10 / 90$ th percentiles of the parameters according to the posterior distributions. The bottom row shows the distributions of the weighted correlation coefficient $\mathrm{r}$ for selected relationships between $\mathrm{P}_{\mathrm{x}}$ and $\beta$, according to 10,000 random samples from the posterior distributions of $\beta$. The dotted line indicates the $10 \%$ significance level.

2010; Dunn et al., 2010], and, more specifically, for its degree of nonlinearity in response.

[26] Such interpretation is further supported by a principal component analysis (PCA) (Figure 5a) of $\alpha, \beta$, the amounts of annual precipitation exceeding various thresholds, and the two catchment characteristics, proportion of responsive soil cover (\%RSC) and drainage density (DD), which were shown by Hrachowitz et al. [2009b] to explain almost $90 \%$ of the variance in MTTs for 21 contrasting catchments in the Scottish Highlands. The first two components (PC 1, PC 2) explain $89 \%$ of the variance in the data and the scores of the individual years scatter in three clusters according to the three catchments. It can be seen that $\beta$ is almost exclusively influenced by PC 1, which shows the highest loadings for the metrics of annual precipitation above various daily thresholds $\left(\mathrm{P}_{5 \mathrm{~mm}}, \ldots, \mathrm{P}_{30 \mathrm{~mm}}\right)$. Parameter $\alpha$, on the other hand is dominated by PC 2 and therefore the high loadings of $\% \mathrm{RSC}$ and $\mathrm{DD}$, although to a minor extent it is also influenced by precipitation metrics and $\beta$.
[27] However, the interpretation of only three catchments is insufficient for inferring statistically significant relationships. A second PCA for spatial analysis therefore additionally included the secondary catchments IDs 4-9 (Figure 1 and Table 1), but was restricted to average TTDs (Table 3) and precipitation characteristics obtained from the entire observation periods. This second PCA tested whether the dependence of $\alpha$ on catchment characteristics, potentially affecting the nonlinearity of response, is generally valid and if additional influences on $\beta$ other than precipitation characteristics emerge with increased sample size (Figure 5b). The first two components explain $84 \%$ of the variance and the overall pattern of the loadings is very similar to the PCA in Figure 5a. This can be seen as more robust evidence that $\alpha$ is most strongly influenced by soil types and catchment organization, here expressed as drainage density.

[28] Godsey et al. [2010] recently showed that $\alpha$ ranged between roughly ca. 0.3 and 0.8 in an analysis of 22 diverse catchments. It was concluded that catchments with large 
a) Inter-annual analysis

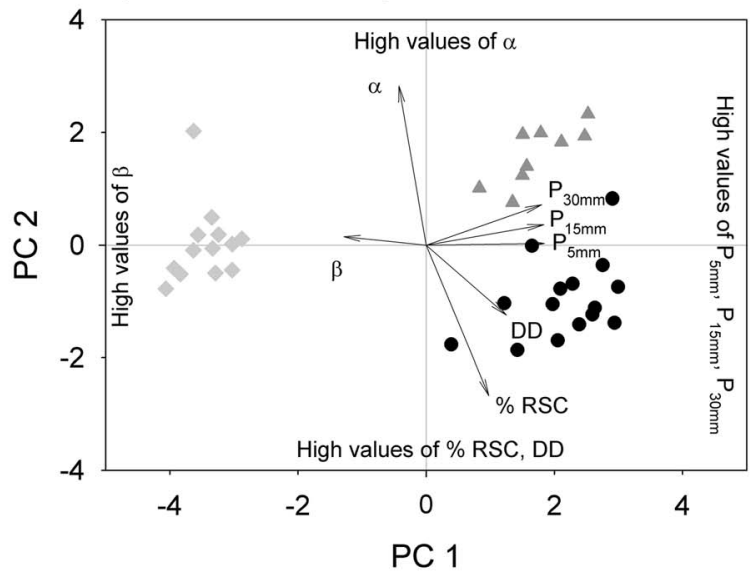

- Strontian
$-\quad$ Balquhidder
Allt a' Mharcaidh b) Spatial analysis

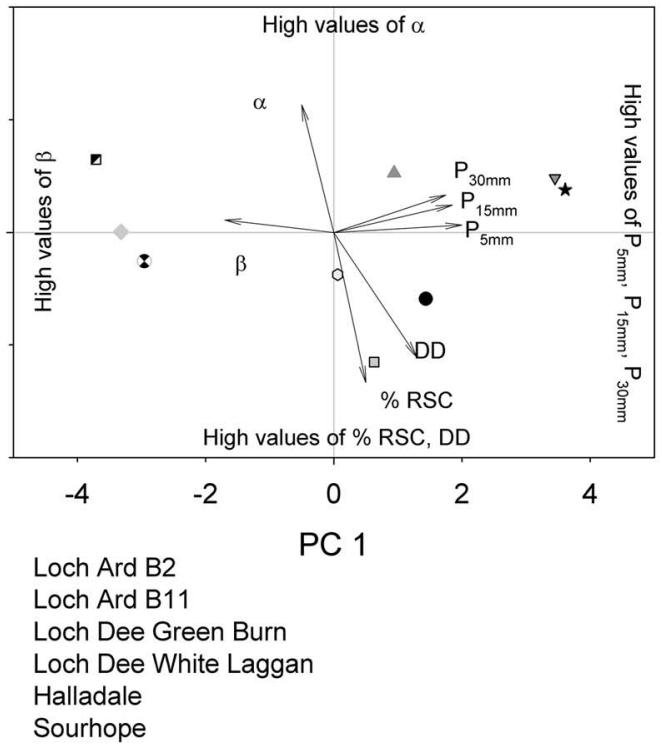

Figure 5. Principal component analysis (PCA) computed with NSE-weighted covariances for (a) interannual analysis of the three primary catchments (IDs 1-3) and annual input values (variance explained by PC 1 and PC 2: 89\%) and for (b) spatial intercomparison of catchment IDs 1-9 with input values averaged over the respective retained observation periods (variance explained: 84\%). Variables used in both PCAs comprised $\alpha, \beta$, proportion responsive soil cover (\%RSC), drainage density (DD), and annual precipitation falling on days with precipitation above the thresholds $5,10,15,20,25,30$, and $30 \mathrm{~mm}\left(\mathrm{P}_{5 \mathrm{~mm}}, \ldots\right.$, $\left.\mathrm{P}_{30 \mathrm{~mm}}\right)$. The component loadings of the individual variables are represented by the length and direction of their respective arrows. For better readability, only $\mathrm{P}_{5 \mathrm{~mm}}, \mathrm{P}_{15 \mathrm{~mm}}$, and $\mathrm{P}_{30 \mathrm{~mm}}$ are shown.

lakes, which showed $\alpha$ values closest to one, are most likely to behave as well-mixed reservoirs. The results of the present study suggest that for these Scottish catchments the values of $\alpha$ seem to be largely controlled by two features, namely the proportion of responsive soil cover and the drainage density, which could potentially be conceptualized as indicators for the level of nonlinearity in tracer inputoutput relationships. Thus, catchments with a high proportion of responsive soils, high drainage densities and low $\alpha$ values are more likely to exhibit comparably high degrees of nonlinearity (i.e., high initial peaks and longer tails in the TTDs) since they rapidly activate preferential flow paths and quickly route water to catchment outlet under wet conditions, while retaining water much longer once the preferential flow paths are no longer active. On the other hand, catchments with high values of $\alpha$ tend to be more freely draining and thus tend toward the hypothetical response of a linear or well-mixed reservoir, i.e., $\alpha=1$, implying lower peaks and reduced weight in the TTD tails.

[29] As estimation of catchment-wide water storage is still a largely unsolved problem, Soulsby et al. [2009] noted the potential for using recent advances in the understanding of catchment transit times [e.g., Hrachowitz et al., 2009b, 2010; Tetzlaff et al., 2009b; Godsey et al., 2010] to estimate total water storage inferred by tracer damping at the catchment scale. Hence, using the well-known relationship between TTD and storage [e.g., Maloszewski and Zuber, 1982] to interpret the results of the present study, the long-term MTT of a given catchment could be expressed as an index of storage. Since, in turn, the average long-term MTT of catchments in the Scottish Highlands is largely dominated by the proportion of responsive soil cover and the drainage density as shown by Hrachowitz et al. [2009b], these two variables could for interpretative reasons be replaced by storage. From this it can be inferred, as a first approximation, that $\alpha$ could also be seen as an index for catchment storage (Figure 5).

\subsection{Time-Variant TTD}

[30] As shown above, the parameter $\beta$ of the TTD of a given catchment is strongly related to high precipitation intensities and amounts falling on days with precipitation above certain thresholds. In order to incorporate this information in the convolution integral method, $\beta$ in the TTDs was expressed as function of the sum of the precipitation amounts of the past, in this case $\mathrm{P}_{30 \mathrm{~mm}}$, as it shows the strongest correlation with $\beta$, exponentially weighted backward in time (equation (8)). Parameter $\alpha$, for which no correlations with climatic variables were found, was held constant.

[31] The estimation of the time-variant $\mathrm{TTD}_{\mathrm{var}}$ in the Strontian catchment (ID 1) was examined over a 4 year period (1994-1997) with comparatively high variation in precipitation (Table 2). As shown in Figure 6, the model period included prolonged periods of relatively low $\mathrm{P}_{30 \mathrm{~mm}}$, as well as very wet periods with higher $\mathrm{P}_{30 \mathrm{~mm}}$. The $\mathrm{Cl}^{-}$ stream response modeled with time-variant TTD $_{\text {var }}$ generally corresponded well with the observed one, with a best fit 


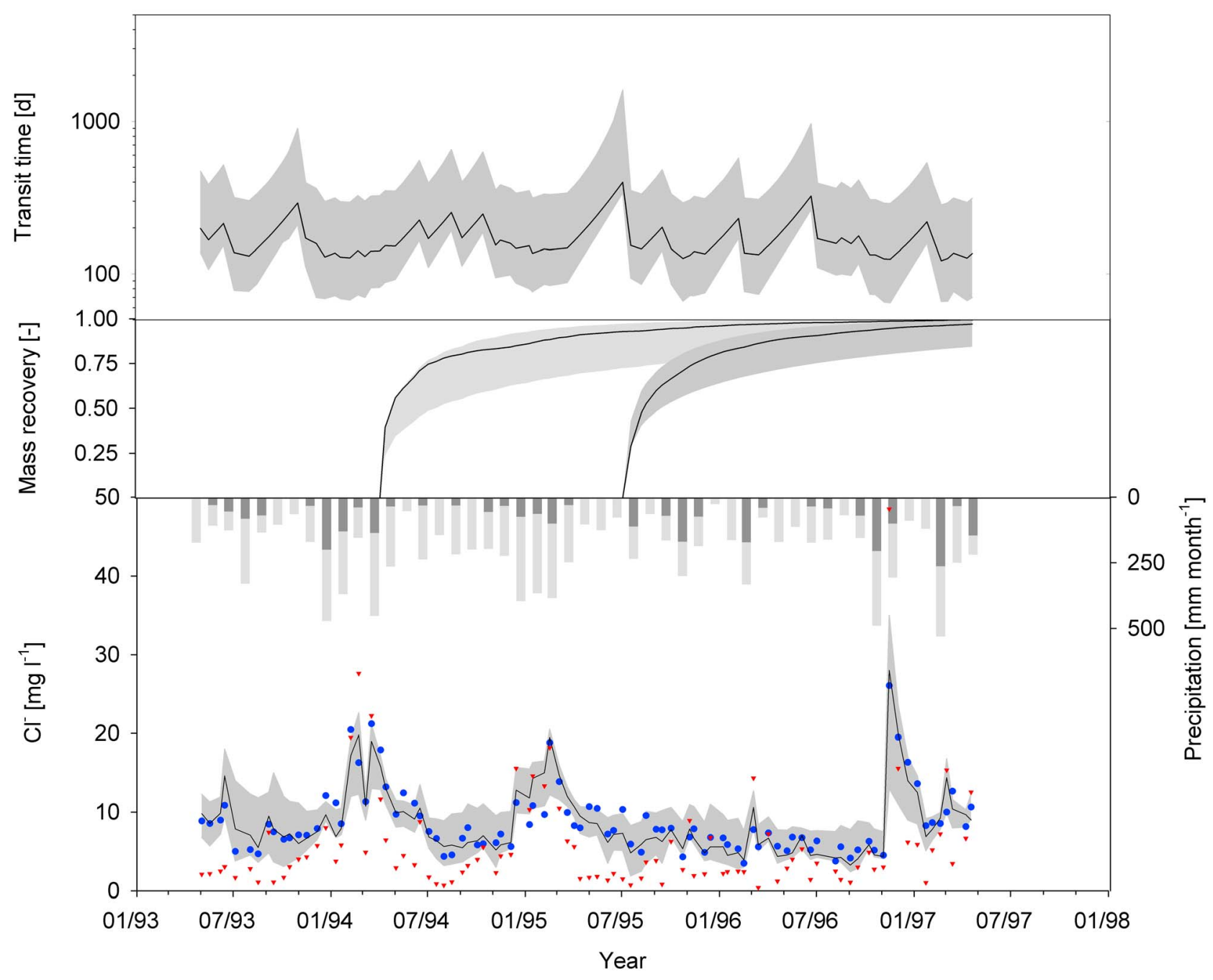

Figure 6. (bottom) Time series of precipitation and $\mathrm{Cl}^{-}$input and output concentrations at Coire nan Con (Strontian, ID 1). Light grey bars are total monthly precipitation, dark grey bars are monthly precipitation amounts falling on days with precipitation $>30 \mathrm{~mm}\left(\mathrm{P}_{30 \mathrm{~mm}}\right)$, inverted triangles are observed $\mathrm{Cl}^{-}$ concentrations in precipitation, blue dots are observed $\mathrm{Cl}^{-}$concentrations in the stream water, the solid black line represents the modeled best fit, and the shaded area is the uncertainty interval for the modeled $\mathrm{Cl}^{-}$stream concentration using a time-variant gamma distribution model for the period 1994-1997. (middle) The mass recovery for two isolated, instantaneous $\mathrm{Cl}^{-}$inputs, with the first one occurring after a period of high antecedent precipitation intensities and the second one occuring after a period of relatively low precipitation intensities. (top) The temporal dynamics of the transit time, with the solid line representing the best fit model. The shaded areas indicate the $5 / 95 \%$ uncertainty intervals.

$\mathrm{NSE}_{\max }=0.83$. The best model fits were obtained using a power law relationship between $\beta$ and cumulative $P_{30 \mathrm{~mm}}$ weighted backward in time:

$$
\beta=\beta_{0}\left(\sum_{i=0}^{t} P_{30 m m_{i}} e^{\left(-\tau_{w} t_{i}\right)}\right)^{-\beta_{1}}
$$

where $\beta_{0}$ is the offset and $\beta_{1}$ the decay parameter.

[32] Linear and exponential relationships were also explored, but they showed poorer model fits together with reduced parameter identifiability. Transit times for the maximum likelihood estimates of $\operatorname{TTD}_{\mathrm{var}}\left(\alpha=0.259, \beta_{0}=\right.$ $1554, \beta_{1}=0.332$ and $\tau_{\mathrm{w}}=0.04$ ) ranged between 120 days during wet periods and 400 days after dry spells (Figure 6).
The modeled transit time fluctuations show a plausible pattern with a mean value of 170 days for the investigated 4 years, compared to the average MTTs of the individual years at Strontian which show a similar mean value of 109 days (Table 3).

[33] Although $\mathrm{NSE}_{\max }=0.83$ for $\mathrm{TTD}_{\mathrm{var}}$ is only a moderate improvement to a time-invariant TTD (i.e., $\beta_{1}=0, \mathrm{NSE}_{\max }=$ $0.80)$, both model selection criteria, $R_{\text {adj }}^{2}\left(R_{\text {adjvar }}^{2}=0.816\right.$ and $\left.\mathrm{R}_{\text {adjinvar }}^{2}=0.797\right)$ and the Bayesian Information Criterion $\left(\mathrm{BIC}_{\mathrm{var}}=122.4\right.$ and $\left.\mathrm{BIC}_{\text {invar }}=125.1\right)$, suggest that the timevariant model structure shows at least an equivalent performance compared to the time-invariant model. In spite of satisfactory model performances and well-constrained values of $\alpha$ (not shown), transit times, especially for dry periods, are 
still poorly constrained, caused by low identifiability of $\beta$ for longer transit times (Figure 4), which is illustrated by the increasing uncertainty interval with increasing transit time. It was, furthermore, observed that the parameter $\tau_{\mathrm{w}}$, which controls the influence of antecedent precipitation, is not identifiable between 0.005 and 1 . It was therefore set to a constant value of 0.04 , which corresponds to a half-life of 25 days, thereby effectively reducing the number of calibration parameters to three.

[34] Isolating two signals of instantaneous tracer input, the first one after a wet period and at the beginning of a dry spell and the second after a relatively dry spell and at the beginning of wetter conditions, clearly shows the effect of time-variant $\mathrm{TTD}_{\mathrm{var}}$ (Figure 6). The first signal, which is injected into the system at the end of a wet period, exhibits fast initial tracer recovery, i.e., a high peak at low transit times, which is gradually flattening out as the conditions become drier and transit times longer. The second signal, injected after a dry period, shows a very low initial tracer recovery, due to long initial transit times. As precipitation increases, the subsequent time steps are characterized by much shorter transit times. Under certain conditions, i.e., a very wet period following a very dry period this can result in a TTD $_{\text {var }}$ peak at a time lag after injection. A delayed TTD peak like that was recently reported by Dunn et al. [2010], using a conceptual model and concluding that a gamma distribution with $\alpha<1$ was thus not suitable to explain the tracer stream signal. Although the climatic conditions before and after the injection of the isolated signal were not specified in that paper, it can be hypothesized that a time-variant gamma distribution as discussed above could partly explain the observed pattern.

[35] While there are a few limitations to the approach presented, such as relatively high parameter uncertainty and the need of relatively long observation periods to infer the most influential precipitation metric, the obvious advantages of using time-variant $\mathrm{TTD}_{\mathrm{var}}$ are, in spite of limited identifiability, that the temporal dynamics of tracer or contaminant fluxes can at least indicatively be followed. This could be potentially important for the management of diffuse pollution in terms of preventative action and mitigation measures after contamination, as time-invariant TTDs are most likely to underestimate the initial contamination pulses under wet conditions and potentially also give an inferior representation of the weights in long tails.

\section{Conclusions}

[36] The gamma distribution, although a mathematically more suitable representation of TTDs than exponential models, has in the past received relatively limited attention in transit time studies. Any physical interpretation of the parameters $\alpha$ and $\beta$ has therefore remained unclear. In this study we used detailed long-term tracer and precipitation data from three catchments and additional long-term average values for six other catchments in the Scottish Highlands to identify the dominant controls on $\alpha$ and $\beta$. While it was found that $\alpha$ largely reflected catchment characteristics, such as the proportion of responsive soil cover, drainage density or storage, $\beta$ was shown to be largely controlled by precipitation events with intensities above catchment-specific thresholds. The relationship between $\beta$ and precipitation characteristics was subsequently used to express $\beta$ as a function of these characteristics within the framework of lumped convolution integrals to estimate TTDs. This resulted in time-variant TTDs, which can give more detailed information about the timing and magnitude of peak tracer fluxes. In the case of the Strontian catchment (ID 1), the general pattern of transit times obtained from time-variant TTDs was shown to be broadly consistent with variations of MTTs from interannual analysis. This suggests that the application of such time-variant TTDs could potentially help to better conceptualize catchment processes and provide a more efficient, realistic representation of effects of unfavorable inputs to contamination-sensitive catchments.

[37] Acknowledgments. This work was funded by the Leverhulme Trust (F/00152/U). The effort of many workers at FRS-Freshwater Laboratory who collected and analyzed the samples in the data collected here is gratefully acknowledged. Similarly, staff at the Macaulay Institute and the Centre for Ecology and Hydrology are thanked for the data from the two ECN sites. Data collection was variously funded by NERC, DEFRA, and the Scottish Government.

\section{References}

Ahmadi-Nedushan, B., A. St-Hilaire, T. B. M. J. Ouarda, L. Bilodeau, E. Robichaud, N. Thiemonge, and B. Bobee (2007), Predicting river water temperatures using stochastic models: Case study of the Moisie River (Quebec, Canada), Hydrol. Processes, 21, 21-34, doi:10.1002/hyp.6353.

Beven, K. J. (2010), Preferential flows and travel time distributions: Defining adequate hypothesis tests for hydrological process models, Hydrol. Processes, 24, 1537-1547, doi:10.1002/hyp.7718.

Boorman, D. B., J. M. Hollis, and A. Lilly (1995), Hydrology of soil types: A hydrologically based classification of the soils of the United Kingdom, Rep. 126, Inst. of Hydrol., Wallingford, U. K.

Botter, F., F. Peratoner, M. Putti, A. Zuliani, R. Zonta, A. Rinaldo, and M. Marani (2008), Observation and modeling of catchment scale solute transport in the hydrologic response: A tracer study, Water Resour. Res., 44, W05409, doi:10.1029/2007WR006611.

Darracq, A., G. Destouni, K. Persson, C. Prieto, and J. Jarsjö (2010), Quantification of advective solute travel times and mass transport through hydrological catchments, Environ. Fluid Mech., 10, 103-120, doi:10.1007/s10652-009-9147-2.

Dunn, S. M., and J. M. Bacon (2008), Assessing the value of $\mathrm{Cl}^{-}$and $\delta^{18} \mathrm{O}$ data in modelling the hydrological behaviour of a small upland catchment in northeast Scotland, Hydrol. Res., 39, 337-358, doi:10.2166/ nh.2008.134.

Dunn, S. M., C. Birkel, D. Tetzlaff, and C. Soulsby (2010), Transit time distributions of a conceptual model: Their characteristics and sensitivities, Hydrol. Processes, 24, 1719-1729, doi:10.1002/hyp.7560.

Ferrier, R. C., and R. Harriman (1990), Pristine transitional and acidified catchment studies in Scotland, in The Surface Water Acidification Programme, edited by B. Mason, pp. 9-18, Cambridge Univ. Press, Cambridge, U. K.

Fiori, A., and D. Russo (2008), Travel time distribution in a hillslope: Insight from numerical simulations, Water Resour. Res., 44, W12426, doi:10.1029/2008WR007135.

Godsey, S., et al. (2010), Generality of fractal 1/f scaling in catchment tracer time series and its implications for catchment travel time distributions, Hydrol. Processes, 24, 1660-1671, doi:10.1002/hyp.7677.

Guan, H., A. Love, C. T. Simmons, Z. Ding, and J. Hutson (2010), Catchment conceptualization for examining applicability of chloride mass balance method in an area of historical forest clearance, Hydrol. Earth Syst. Sci., 14, 1233-1245.

Hrachowitz, M., C. Soulsby, D. Tetzlaff, J. J. C. Dawson, S. M. Dunn, and I. A. Malcolm (2009a), Using long-term data sets to understand transit times in contrasting headwater catchments, J. Hydrol., 367, 237-248, doi:10.1016/j.jhydrol.2009.01.001.

Hrachowitz, M., C. Soulsby, D. Tetzlaff, J. J. C. Dawson, and I. A. Malcolm (2009b), Regionalization of transit time estimates in montane catchments by integrating landscape controls, Water Resour. Res., 45, W05421, doi:10.1029/2008WR007496.

Hrachowitz, M., C. Soulsby, D. Tetzlaff, and M. Speed (2010), Catchment transit times and landscape controls-Does scale matter?, Hydrol. Processes, 24, 117-125. 
Johnson, R. C. (1991), Effects of upland afforestation on water resources, Rep. 116, Inst. of Hydrol., Wallingford, U. K.

Kirchner, J. W., X. Feng, and C. Neal (2000), Fractal stream chemistry and its implications for contaminant transport in catchments, Nature, 403, 524-527, doi:10.1038/35000537.

Kirchner, J. W., X. Feng, and C. Neal (2001), Catchment-scale advection and dispersion as a mechanism for fractal scaling in stream tracer concentrations, J. Hydrol., 254, 82-101, doi:10.1016/S0022-1694(01) 00487-5.

Kirchner, J., D. Tetzlaff, and C. Soulsby (2010), Comparing chloride and water isotopes as hydrological tracers in two Scottish catchments, Hydrol. Processes, 24, 1631-1645, doi:10.1002/hyp.7676.

Laudon, H., V. Sjöblom, I. Buffam, J. Seibert, and M. Mörth (2007), The role of catchment scale and landscape characteristics for runoff generation of boreal streams, J. Hydrol., 344, 198-209, doi:10.1016/ j.jhydrol.2007.07.010.

Lindgren, G. A., G. Destouni, and A. V. Miller (2004), Solute transport through the integrated groundwater-stream system of a catchment, Water Resour. Res., 40, W03511, doi:10.1029/2003WR002765.

Maloszewski, P., and A. Zuber (1982), Determining the turnover time of groundwater systems with the aid of environmental tracers: 1 . Models and their applicability, J. Hydrol., 57, 207-231.

Maloszewski, P., and A. Zuber (1996), Lumped-parameter models for the interpretation of environmental tracer data, in Manual on Mathematical Models in Isotope Hydrology, Rep. IAEA-TECDOC-910, pp. 9-58, Int. At. Energy Agency, Vienna.

McDonnell, J. J., et al. (2010), How old is streamwater? Open questions in catchment transit time conceptualization, modeling and analysis, Hydrol. Processes, 24, 1745-1754, doi:10.1002/hyp.7796.

McGlynn, B., J. McDonnell, M. Stewart, and J. Seibert (2003), On the relationships between catchment scale and streamwater mean residence time, Hydrol. Processes, 17, 175-181, doi:10.1002/hyp.5085.

McGuire, K. J., and J. J. McDonnell (2006), A review and evaluation of catchment transit time modeling, J. Hydrol., 330, 543-563, doi:10.1016/j.jhydrol.2006.04.020.

McGuire, K. J., J. J. McDonnell, M. Weiler, C. Kendall, C. L. McGlynn, J. M. Welker, and J. Seibert (2005), The role of topography on catchment-scale water residence time, Water Resour. Res., 41, W05002, doi:10.1029/2004WR003657.

Neal, C., and J. Kirchner (2000), Sodium and chloride levels in rainfall, mist, streamwater and groundwater at the Plynlimon catchments, midWales: Inferences on hydrological and chemical controls, Hydrol. Earth Syst. Sci., 4, 295-310, doi:10.5194/hess-4-295-2000.

Neal, C., N. Christopherson, R. Neale, C. J. Smith, P. G. Whitehead, and B. Reynolds (1988), Chloride precipitation and streamwater for the upland catchment of River Severn, mid-Wales: Some consequences for hydrochemical models, Hydrol. Processes, 2, 155-165, doi:10.1002/ hyp. 3360020206 .

Rodhe, A., L. Nyberg, and K. Bishop (1996), Transit times for water in a small till catchment from a step shift in the oxygen 18 content of the water input, Water Resour. Res., 32, 3497-3511, doi:10.1029/95WR01806.

Schoups, G., and J. A. Vrugt (2010), A formal likelihood function for parameter and predictive inference of hydrologic models with correlated, heteroscedastic, and non-Gaussian errors, Water Resour. Res., doi:10.1029/2009WR008933, in press.

Shaw, S. B., A. A. Harpold, J. C. Taylor, and T. M. Walter (2008), Investigating a high resolution, stream chloride time series from the Biscuit Brook catchment, Catskills, NY, J. Hydrol., 348, 245-256, doi:10.1016/j.jhydrol.2007.10.009.

Soulsby, C., M. Chen, R. C. Ferrier, A. Jenkins, and R. Harriman (1998), Hydrogeochemistry of shallow groundwater in a Scottish catchment,
Hydrol. Processes, 12, 1111-1127, doi:10.1002/(SICI)1099-1085 (19980615)12:7<1111::AID-HYP633>3.0.CO;2-2.

Soulsby, C., R. Malcolm, R. C. Helliwell, R. C. Ferrier, and A. Jenkins (2000), Isotope hydrology of the Allt a'Mharcaidh catchment, Cairngorm mountains, Scotland: Implications for hydrological pathways and water residence times, Hydrol. Processes, 14, 747-762, doi:10.1002/(SICI) 1099-1085(200003)14:4<747::AID-HYP970>3.0.CO;2-0.

Soulsby, C., D. Tetzlaff, P. Rodgers, S. M. Dunn, and S. Waldron (2006), Runoff processes, stream water residence times and controlling landscape characteristics in a mesoscale catchment: An initial evaluation, J. Hydrol., 325, 197-221, doi:10.1016/j.jhydrol.2005.10.024.

Soulsby, C., D. Tetzlaff, and M. Hrachowitz (2009), Tracers and transit times: Windows for viewing catchment scale storage?, Hydrol. Processes, 23, 3503-3507, doi:10.1002/hyp.7501.

Stewart, M. K., and J. J. McDonnell (1991), Modeling base flow soil water residence times from deuterium concentrations, Water Resour. Res., 27, 2681-2693, doi:10.1029/91WR01569.

Stott, T. (1997), A comparison of stream bank erosion processes on forested and moorland streams in the Balquhidder catchments, central Scotland, Earth Surf. Processes Landforms, 22, 383-399, doi:10.1002/(SICI) 1096-9837(199704)22:4<383::AID-ESP695>3.0.CO;2-4.

Tetzlaff, D., C. Soulsby, S. Waldron, I. A. Malcolm, P. J. Bacon, S. Dunn, and A. Lilly (2007a), Conceptualization of runoff processes using tracers and GIS analysis in a nested mesoscale catchment, Hydrol. Processes, 21, 1289-1307, doi:10.1002/hyp.6309.

Tetzlaff, D., I. A. Malcolm, and C. Soulsby (2007b), Influence of forestry, environmental change and climatic variability on the hydrology, hydrochemistry and residence times of upland catchments, J. Hydrol., 346, 93-111, doi:10.1016/j.jhydrol.2007.08.016.

Tetzlaff, D., J. Seibert, and C. Soulsby (2009a), Inter-catchment comparison to assess the influence of topography and soils on catchment transit times in a geomorphic province; the Cairngorm mountains, Scotland, Hydrol. Processes, 23, 1874-1886, doi:10.1002/hyp.7318.

Tetzlaff, D., J. Seibert, K. J. McGuire, H. Laudon, D. A. Burns, S. M. Dunn, and C. Soulsby (2009b), How does landscape structure influence catchment transit times across different geomorphic provinces, Hydrol. Processes, 23, 945-953, doi:10.1002/hyp.7240.

Turner, J. V., D. K. Macpherson, and R. A. Stokes (1987), The mechanisms of catchment flow processes using natural variations in deuterium and oxygen-18, J. Hydrol., 94, 143-162, doi:10.1016/0022-1694(87) 90037-0.

Vrugt, J. A., C. J. F. ter Baak, C. G. H. Diks, B. A. Robinson, J. M. Hyman, and D. Higdon (2009), Accelerating Markov chain Monte Carlo simulation by differential evolution with self-adaptive randomized subspace sampling, Int. J. Nonlinear Sci. Numer. Simul., 10, 273-290.

Weiler, M., and J. J. McDonnell (2004), Virtual experiments: A new approach for improving process conceptualization in hillslope hydrology, J. Hydrol., 285, 3-18, doi:10.1016/S0022-1694(03)00271-3.

Weiler, M., B. L. McGlynn, K. J. McGuire, and J. J. McDonnell (2003), How does rainfall become runoff? A combined tracer and runoff transfer function approach, Water Resour. Res., 39(11), 1315, doi:10.1029/ 2003WR002331.

M. Hrachowitz and G. Schoups, Water Resources Section, Faculty of Civil Engineering and Geosciences, Delft University of Technology, PO Box 5048, NL-2600 GA Delft, Netherlands. (m.hrachowitz@tudelft.nl)

I. A. Malcolm, Freshwater Laboratory, Marine Scotland, Pitlochry PH16 8AA, UK.

C. Soulsby and D. Tetzlaff, Northern Rivers Institute, School of Geosciences, University of Aberdeen, St. Mary's, Aberdeen AB24 3UF, UK. 